\title{
Why Listening to English Is Difficult for Spanish Students
}

\author{
John K. Eastman \\ Universidad de Alicante
}

\begin{abstract}
We examine the educational and cultural influences as well as some of the psychological and pedagogical factors which conspire to make listening comprehension difficult for Spanish students of English. We propose exercises which students should undertake as preparation and training for listening, and suggest an approach to the presentation and teaching of listening material.
\end{abstract}

\section{Background}

After the Gutenberg revolution, the world became literate. As our forebears learnt to read, they gradually lost their faculty for aural learning and aural memorization. We have become far more dependent on the written word and pictorial presentation than they were. Compare how much we learn from reading and how much from listening. We do not trust our aural memories; we take notes in lectures and rely on visual input to memorize information. How many of us today could hear a saga recited but once, and recall, if not all, large parts of it? 500 years ago, the ability to do this was far more common, simply because the aural memory was the only resource people had. Yet it is this atrophied, under-used faculty the learner of spoken English has to use, with the added handicap that he cannot mentally visualize the words he hears, because many phonemes in English have no parallel in Spanish.

Against this background, most Spanish EGB and BUP students (Ss) are taught English in large classes rarely less than 40 strong. The significance of this is that many teachers, fearing loss of class control, do not permit practice sessions of pair or group work, discussions, debates and listening comprehension (LC). Also, the enormous yearly syllabus imposed by the education authorities means that to complete it in the time available (even with no disciplinary problems), teachers can do little more than race through the programme; there is no time for practice. Given these strictures, EGB/BUP English classes are often reduced to grammar explanations and the translation of extracts from various literary works.

Reading and listening are both input skills using similar processes and linguistic knowledge, so when the $\mathrm{S}$ eventually comes to listening to English, it is quite natural 
for him to attempt word-by-word translation, often with the aim of $100 \%$ comprehension. (There are other, psychological, forces at work driving him to translate as he listens, as we shall see.) This strategy, however, is mistaken: it is laborious in the extreme, requires very high levels of competence in both languages, which the learner manifestly does not have, and is based on the assumption that the two forms of input can be tackled in the same way. The translating listener does not realize that when he is reading, he can read and re-read a whole sentence while trying to translate it. He also may not know that the phonological realization of English has almost nothing to do with its graphological form, at least as far as most vowels and some consonants are concerned. . $^{2}$

This discrepancy is part of yet another problem facing the Spanish S: what aspects of the spoken language he should attend to. If he attends to all syllables, as he does when listening to Spanish, his attentional capacity will be overwhelmed. The learnerlistener naturally tends to do this whether he translates or not. Part of the learning process involves learning to attend to stressed syllables and the words that contain them (since these carry the bulk of meaning) and relegate to peripheral attention the unstressed syllables and function words. This is main aim of the RSL exercises in section $3 .^{2}$

The S's attitude to learning in general does not help him either. Perhaps because of the inhuman demands of the syllabuses (most school subjects are overladen with content and beyond the reach of all but the most assiduous student), he studies only half-heartedly. Perhaps because he is required to learn swaths of matter by heart, he mistakenly believes that language learning, like any other subject, is mainly a matter of knowing facts ( gato $=$ cat, silla $=$ chair, coger $={ }^{*}$ catch), and that learning vocabulary lists is virtually all he requires. Fact learning-declarative knowledge or knowing 'that'-is given very great importance, not only in education, but throughout Spanish culture. ${ }^{3}$ The other sort-procedural knowledge or 'knowing how'-plays only a minor part in his life, and S may not recognize it for what it is. He may not appreciate that in mathematics he learns that $2+2=4$ and $3 \times 4=12$, but then repeatedly applies this knowledge in practical problems, demonstrating his procedural knowledge, which at the same time reinforces his declarative knowledge and accelerates its production.

So both the culture and more immediate obstacles combine to prevent the $S$ from having much language practice in the classroom. Listening to a foreign language requires the application of procedural knowledge to declarative knowledge in unrelenting conditions, and is complicated by the factors outlined earlier. Practice is therefore one of the main keys to auditory comprehension; $\mathrm{S}$ must use vocabulary and syntax repeatedly until meanings and structures are instantly accessible. It is not widely appreciated that learning how to do something takes much more time than learning facts. As O'Malley, Chamot and Walker say:

The distinction between declarative knowledge and procedural knowledge has both theoretical and practical importance for SLA. Knowing about language as a grammar system (rules underlying syntax, semantics and phonology) is not a sufficient condition for knowing how to use a language functionally. (295)

To add to his difficulties, there are S's very natural, logical, reasonable expectations that English will work much like Spanish: that the written form will reflect the spoken, 
that there is a one-to-one relation between concepts, that vowels will convey as much information as consonants (see again note 2) and that syntax will also be similar. Having studied English in its written form, the Spanish $\mathrm{S}$ finds it difficult to adjust to the fact that very few words are pronounced in anything like their written form (see again note 1). This has two main effects: he invests his spoken English with the same syllable-timing as Spanish has, and pronounces exactly what he reads. The spoken English he hears, however, meets few of his expectations and makes LC even more difficult for him.

One way round this problem would be to teach English orally, without books. However, given our dependence on visual input, our over-riding need to see what we hear in order to 'fix' it in our memories, this is not practicable. A good compromise would be to present English in phonetic form, so that $\mathrm{S}$ does not read any real written English for perhaps the first two years. ${ }^{4}$ This has the advantages of allowing accentless production and making learning much easier. Such a change might be too radical for State schools, however, and until this happens, those teaching LC will have involve remedial work with most Ss, who will need to contribute their fair share of the effort.

\section{Mental Processes}

Current thinking in psychology on attention derives in large part from Schiffrin \& Schneider's work on information-processing theory. They state that mental operations vary in their requirements for attentional capacity, and attentional capacity is limited and fluctuates according to arousal, mood and task demand. Mental operations are either automatic or controlled. Automatic processes, such as extracting meaning from printed words (reading), use no attentional capacity. Controlled operations use attentional capacity, but can become automatic through practice.'So we can concurrently run two or more controlled processes so long as they do not exceed attentional capacity.

When we listen to our mother tongue, word meanings are automatically accessed; we then use our spare attentional capacity (1) to anticipate what the speaker is going to say by referring to what knowledge we already have about the topic, (2) to infer meanings incomplete through ellipsis, inadequate expression or ambiental noise, (3) to observe facial expressions and body language, and (4) to infer the speaker's attitude to and emotions on the topic.

If, on the other hand, we are so unfamiliar with phonological realizations, meanings and syntax that we use up all our attentional capacity in determining them, we shall have no spare attentional capacity for these processes (anticipating, inferencing etc.). If meanings are not instantly available (i.e. automated), we have to search for them, which operation exceeds attentional capacity, overloads the system and causes the comprehension process to break down. Hence the importance of learning meanings so well they are produced without effort. Not overlearning meanings is one the major causes of Ss trying to translate while they listen.

$\mathrm{S}$ must therefore automate as many subskills as possible to be able to anticipate and infer in L2. The main subskills are: instant recognition of word meanings (which involves instant recognition of word pronunciations), practice in attending to stressed syllables (leaving reduced forms for peripheral attention), using 'chunked' stressed 
syllables to extract meaning, and using the spare attentional capacity for prediction and inferencing. 'Chunked' stressed syllables, or 'syntactic chunking' is the process of attending to groups of words which are syntactically related rather than to separate words. Attention is focused centrally on the stressed syllables but only peripherally on the unstressed (which carry less information). The ability to do this conues from practice. In the early stages, the beginner identifies only isolated words and cannot 'chunk,' except by guessing or inferencing some sort of relationship between them.

\section{Memory}

Our auditory memory has three parts: echoic, short-term (STM) and long-term (LTM). The echoic takes in raw sound and passes it to the STM, which segments it into meaningful 'chunks,' interprets it and sends the result to the semantic-associational LTM for storage. The STM is very limited both in span and in the time it can hold information, and it is even more limited in L2. Chunked material sent to the LTM is purged from the STM to make room for more input.

Information is stored in the LTM in some abstract form, not in words, and is related by meaning to information already there. When information is not comprehended, it can be stored in LTM as sounds (phonemically), and this occurs especially when there is a simultaneous demanding supplementary task and/or there is insufficient time to produce semantic links. These conditions occur precisely when the listener is translating into $\mathrm{Ll}$ (demanding task) and/or when the listener is not sufficiently familiar with meanings (insufficient time to make links). Obviously, where the listener has to translate, he is likely to store information in $\mathrm{Ll}$, which will require later translation into $\mathrm{L} 2$ when he must produce answers to comprehension questions. Usually, however, phonemic storing processes overload the system, and the listener stops listening, perhaps to start again at the beginning of a new sentence.

LTM is thought to be organized in two stores: the semantic store which contains information learnt from books, and the episodic store, which holds information from personal experience. Recall is dependent on elaboration of connections between the various parts (connecting the 'new' to the 'old' information: the greater the number of connections, the more is remembered. Rehearsal of information is also important for recall; information not rehearsed becomes more difficult to recall.

Within the semantic store, memory is also thought to be organized into 'scripts' or schemata. Thus when we go to a restaurant, we use the restaurant script: we expect the waiter to show us to a table, bring us a menu, write down our order, bring it to us, and later take our money. When we hear a passage about a visit to a restaurant, so script theory states, we activate that script, and so can anticipate at least some of the events which will transpire, freeing attentional capacity. Access to such scripts will be denied us if our attentional capacity is overloaded with puzzling out meanings of individual words, and attempting to translate what we hear. Increasing competence in LC means less effortful work, not more. 


\section{Other Factors}

Factors which drive the learner-listener to translate while listening are both psychological and pedagogical in nature. If a $S$ has performed poorly at listening, he may develop an attitude to the activity which reflects this inadequacy, namely a form of anxiety. (The $T$ should then do his best to show $S$ that failure to comprehend this text is of litle importance and that he should relax-and overlearn meanings in context for future listenings - by maintaining an unconcerned attitude to poor individual performance.) Stress or anxiety during listening activities, arising from inability to comprehend on previous occasions, has the effect of limiting the focus of attention to central information and allowing only automatic processes to function. The novice learner most probably does not know what the central information is (basically stressed syllables) and has few automatic processes (i.e. instant accessing of meanings from words).

Inadequate presentation of listening material is another cause of negative attitudes, anxiety, poor performance and attempts to translate. This aspect is dealt with in Section III. The low proficient listener, focusing on words and not yet 'chunking,' uses all his attentional capacity on identifying isolated words. He has no spare capacity to access his world knowledge store (scripts) and must treat the message as 'new' information which has no context and therefore no script. This means that he cannot predict sentence-ends or anticipate events, which would also make LC easier for him.

\section{How to Teach Listening Comprehension}

Strictly, we cannot teach a $\mathrm{S}$ to listen and comprehend; we can only help him to practise and learn. However, the procedures which best help $\mathrm{S}$ to learn to comprehend are not widely known. For example, Hutchinson, in his guide to teachers in an otherwise excellent second year book, Project English, proposes that T should allow Ss to read the scripts of what they are listening to. Clearly, given our overpowering eye-dependency, Ss will comprehend what they read, not what they hear. They will not make the aural effort, and will not learn to comprehend aurally. I maintain that learners should never read the texts they are hearing, have heard or will hear. I shall propose here only what I believe to be correct procedures for 'teaching' LC.

Ts can make Ss' aims explicit while learning English (and not only while listening). These aims are:

1. To make English as independent from $\mathrm{Ll}$ as possible; this he can achieve in the early stages by learning to attach the meanings of English words to the objects-referent, not to the mother-tongue equivalent, in the later stages by using words in sentences meaningful to himself via RSL exercises (see section 3 ).

2. To think as much as possible in English; this will involve him thinking or saying to himself simple phrases in English, or keeping a diary in English. This is rehearsal (or practice) which is probably the most important factor in memorization or learning any skill). It also means that $\mathrm{S}$ learns English syntax en passant. 
3. To avoid translation, particularly when reading and listening.

4. To aim at understanding the gist, not $100 \%$, of the message.

To achieve aims 1 and $2, \mathrm{~S}$ will have to apply himself to the exercises outlined below, which should help him achieve aim 3. T's approach to listening should help $S$ in aim 3 if he follows the procedures we suggest.

Another way the T can ease the S's learning is to tell him of the various strategies he can adopt, distinguishing between those taken up by proficient listeners and those by unskilled listeners. Because strategies are conscious, controlled processes, the listener can deliberately (attempt to) apply them.

Low Proficient Student

Stops listening when he meets an unknown word or phrase

Listens for each word, words and phrases

\section{Elaborations}

Makes fewer elaborations

Does not relate new information to his own life
High Proficient Student

-monitoring: maintaining awareness of task demands and information content

- selective attention-focusing on specific information anticipated in the message

- directed attention-focusing more generally on task demands and content

- elaborating or relating new information to prior knowledge

- inferring or guessing at meaning from context

- or complete missing ideas

Aware when he stops attending; makes an effort to redirect attention to task

Listens for intonation and pauses, phrases and sentences

Uses his world knowledge personal knowledge

Anticipates what the speaker may say

Table 1: Summary of strategies during listening comprehension by high and low proficient listeners. Derived from O'Malley et al. Listening Strategies. 
O'Malley et al (Listening Strategies) have investigated what high and low proficient listeners do while they listen. Their findings are summarized in table 1 . In their study, translation while listening did not bulk large. It was briefly noted as 'problematic' and was more often used by low proficient listeners, who recognized it as highly inefficient. It was also preferred by Ss from classes where grammar is emphasized (Chamot and Kupper). The fact that translation was an infrequently-mentioned strategy is almost certainly due to the fact that American Ss do not have such a heavily grammar-reading-translation basis in their L2 learning as occurs in Spain. We can of course argue that O'Malley's high proficient listeners may simply have had more practice than the low, but telling Ss to be aware of their mental activities, the $T$ is suggesting short cuts, and advising against fruitless effort. There are other implications in O'Malley's work which relate to attention and memory processes, as well as indications that the high proficient listener is more in charge of his mental processes than the low proficient. We shall examine the mental processes involved in LC in Section II.

The $\mathrm{S}$ requires long-range continuous preparation if he is to learn to listen. Fortunately, the basic training he must undergo will not only permit him to understand spoken English with few problems, but will teach him syntax and give him practice in speaking, reading and writing. As with all learning, it takes time, but if it is done on a regular daily basis, it should be relatively painless, occupying perhaps ten minutes a day. Here we outline the sorts of exercises which will make listening an easily-acquirable skill.

It should be clear from the foregoing that a sine qua non for successful LC is for the $S$ to have overlearnt vocabulary and syntax, in order to be able to access meanings instantly. In other words, he must automate them. The most intelligent and interesting way of doing this is for S to relate $\mathrm{L} 2$ to his personal life by making up sentences, preferably vivid, which are real for him, which relate real-life episodes. E.g.

My brother is a pig. He broke my favourite record

I live in a large flat on the third floor

I was given a bicycle when I was seven

Yesterday I bought a shirt and a pair of trousers

He could also deliberately use function words:

I like my shirt, but brother doesn't

and so on. You can direct Ss to use specific structures which have just been taught, or include irregular verbs in specified tenses, irregular plurals and the rest, to ensure that these are used.

A second essential is for Ss to learn phonetics. Until English becomes phonemic, and while we persist in teaching English using normal orthographical forms, ss must also learn how the language works phonologically. If there is little time for teaching phonetics, then limit yourself to teaching the vowel sounds, especially the reduced forms and when and where they occur, and a rule-of-thumb guide to pronunciation. ${ }^{5}$ Then you can correct Ss' real-life vivid sentences and tell him to cross out the schwas and underline the stressed syllables. He can then use these sentences as RSL exercises 
(see below), a far more practical, meaningful way of learning vocabulary, syntax and pronunciation than trying to learn vocabulary in contextless lists. Admittedly it is time-consuming, but it produces better results than rotelearning paired associates (cat = gato), which encourages translating, because he is relating words to each other in L2, and to his personal experience.

\section{Read, Say and Listen Exercises}

These exercises are based on the assumption that comprehension is a product of both input and expectations. Where the listener's expectations are in line with what he hears, he is more likely to comprehend than if they are inaccurate. Accurate expectations make the listener less dependent on the phonological aspects of input, in that he applies less attention capacity to the signal, thus freeing capacity for inferencing and anticipating what the speaker is going to say, and relating the message to his prior knowledge.

RSL exercises are probably most crucial for the early learner. Their aim is to teach $\mathrm{S}$ to focus his attention on the stressed syllables in phrases, and to relegate to peripheral attention those which are unstressed. They also teach him the rapid pronunciation of reduced forms and may succeed in making the $\mathrm{S}$ listen to himself.

The principle is to have the Ss repeat rhythmically (at roughly equal time intervals) the stressed syllables of a phrase (perhaps one which will occur in an upcoming LC passage), and then to repeat that with the reduced syllables interposed while maintaining the original rhythm. This can all be repeated with increased pace until Ss are saying the phrase at native speech rate. Intonation can also be incorporated. So

$\begin{array}{llll}\text { PEOP } & \text { THOUGHT } & \text { EARTH } & \text { FLAT }\end{array}$

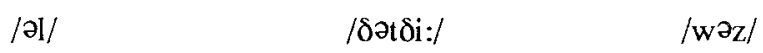

or

$\begin{array}{llll}\text { WHO } & \text { OFF WHEN }\end{array}$

$$
\text { /wazəठi:/ /is/ /juə/ /bədi/ }
$$

Building long phrases can also fit in this type:

I THINK

I THINK that there MAY

I THINK that there MAY be inTELLigent LIFE ...

which are sometimes more easily achieved by back-chaining: 
where the capitals are pronounced at roughly equal time intervals. The exercise can be adapted to single polysyllabic words to inculcate the idea that most words have one stressed syllable, the others being reduced to schwa or short 'i.' E.g.:

The word 'America' contains two / $/$. Cross out those syllables which are pronounced $/ \partial /$ :

$\begin{array}{llll}\text { iron } & \text { century } & \text { paper } & \text { correct } \\ \text { adults } & \text { fibre } & \text { important } & \text { machine } \\ \text { Africa } & \text { countries } & \text { serious } & \text { somebody } \\ \text { Germany } & \text { industries } & \text { elephant } & \text { Canada }\end{array}$

Now underline the stressed syllables.

(from Swan and Walker)

This exercise can be used to focus on different suprasegmental patterns:

\section{A: WHERE do you LIVE? B: THESE BOOKS are CHEAP}

$\mathrm{A}$ or $\mathrm{B}$ ?

Green eyes are nice

First on the left

Four pints of beer

Why did you go?
Jill works at home

Six pounds of meat

She's got a cold

What have you done?

\section{Prediction exercises}

(from Swan and Walker)

Prediction of sentence-ends begins to occur only when syntactic 'chunking,' and processes which relegate parts of the input to peripheral attention (such as the informationally less important syllables containing reduced vowels) leave spare capacity in the attention mechanism. The less proficient learner is unlikely to be able to avail himself of these processes, because he cannot yet 'chunk' or relegate. However, the following exercises should begin to make them occur.

Prediction-training exercises that can precede a listening activity may be carried out in groups or individually. They include:

- ordering pictures showing scenes from the text to be heard;

- predicting likely events and vocabulary, given the text title;

- thinking about or discussing the text topic

for $\mathrm{T}$ to tell a parallel version of the story, then stop half-way through a sentence to allow Ss to suggest completions, $T$ perhaps using preposed subclauses, Ss supplying the main clauses.

Sentence completion could also target single, words, including connectors, as well as clauses, and even the sentence following one read out by $\mathrm{T}$. At discourse level, given the topic title, SB might suggest how a speaker might organize his speech. (This is parallel to paragraph-planning in composition writing, with the obvious implications for post-listening activities at intermediate level.) 
For maximising the use of time and SB' chances of exposure, $T$ needs to take four steps:

1. Contextualising the tape

2. Pre-sensitization

3. Exposure to aural message

4. Feedback

At intermediate level and beyond, step 2 is, or should be, superfluous, apart from the teaching of new words and phrases too difficult to infer from context.

\section{Contextualizing the Tape}

Context, so plentifully supplied on video tape, in establishing shots, body language, facial expressions and the like, permit a degree of contextualization lacking in audio-tapes. To compensate for this lack, some context must be given. The simplest way is to give the message a title or headline which will direct $\mathrm{SB}^{\prime}$ mind set to the events and outcomes and therefore the vocabulary which may be used. A brief description of the characters, their ages, relationships and attitudes, the time and place of action-in fact anything that will help the mise en scene. Where predictions are confirmed, the S's need to process every word should be reduced, in turn allowing him to access real world knowledge and make further predictions. Useful, too, is the process of asking SB to predict what may happen, (given some basic information) which encourages the production of vocabulary which may arise, as well as possible events.

Visual support also helps to contextualize and reinforce the message, assist prediction and can indicate comprehension where SB draw or write on answer sheets. These can take any suitable form such as graphs and diagrams which must be completed, pictures which may (not) summarize the passage, routes to be followed on maps, faces which may be persons referred to. For more abstract themes, such support might consist of the key words and phrases from each paragraph.

Arnold and Brooks' work with children found that the effect of visual support material before listening significantly affects comprehension and recall of otherwise inexplicit prose. Mueller's study showed that comprehension was improved if the visual cues were given before or immediately after presentation of a passage. Furthermore, he found that visuals enhanced comprehension in inverse ratio to SB' proficiency. It appears that visual support is far more helpful to beginners who can make less use of linguistic cues. Written comprehension questions and working on closely-related topics but in different modes will also provide context to an imminent listening activity.

\section{Pre-Sensitization}

Especially useful at the lower levels is the presentation of vocabulary items and phrases which are new to them. This has the twin advantages of hinting at events and reducing the number of possible events, thus assisting prediction. It is best done by presenting on the board new or key words or phrases in phonetics which the SB repeat several times before the translation is given. (Translation before listening is acceptable.) This exercise (RSL) should facilitate explicit guessing about the topic, SB pooling their knowledge. 
After the passage has been heard for the final (third?) time, the spellings can also be given.

\section{Exposure to the Aural Message}

The tape is played once; at lower levels you can ask what words and phrases SB heard. All offerings, right or wrong, can be accepted as right, or at most met with a quizzical look from T. This rather unethical proceudre is to avoid quashing Ss' other guesses. (No-one likes being publicly wrong.) A variant on this is to use the zero-feedback technique, where all answers are met with a neutral gesture by $\mathrm{T}$, awaiting confirmation in second and third playings.

The tape can then be played a second time, the Ss repeating and amplifying the words and phrases they have heard. Finally, you play the tape a third time. Playing it any more will suggest that understanding this tape is important, and may sow the seeds of anxiety in those SB who have understood little. You can then ask comprehension questions, or check the answers on their visual support sheets (maps, graphs etc).

The exercises and tasks Ss carry out while listening should not require very much processing capacity, or their attention will be distracted from listening, which is always the superordinate activity. Thus diagrams, graphs and maps will be simple, even puerile, when seen in isolation, but they should have some element of challenge. They may be accurate and await confirmation thorugh understanding, inaccurate and require correction or omit some information to be supplied by $\mathrm{S}$, or an amalgam of these.

\section{Feedback}

Feedback is implicit; those who have grasped the gist will already know it, and will need confirmation that they are right. Those who have not understood will also know it, and you must try to single these Ss out and ask them simple questions to give them some reward for whatever little they have grasped. This can take the form of how many people? was one angry? and the like.

Ss can be encouraged to report what happened, complete oral statements you make about the passage, summarize it, choose or create a title, either in groups or as a class exercise. Producing a written summary takes too long, however, as homework is too removed in time from the hearing to yield an accurate precis. For those who have understood little, it is advisable to assure them that this is unimportant, that they will understand more next time.

You can also use written comprehension questions. They can take a variety of forms (comprehensively listed in Ur), but should never be verbatim extracts from the passage, but paraphrases. These should take the form of declarative statement and be short. The questions should vary in difficulty, coincide in order of occurrence of events, and avoid detail except where this is crucial (e.g. flight numbers and times). Brown (Investigating Listening Comprehension) points out that failure to answer such questions does not necessarily mean that $S$ has not comprehended the passage, as he may not have understood the specification of the task, or he may be unable to reflect in the task the extent of his comprehension, which underlines the care we should take in phrasing our questions. 
Multiple choice answers should also be paraphrastic, and can be made to vary in difficulty by the degree of semantic differentiation between the choices, as well as offering different possibilities. Multiple choice has the advantage over free responses (apart from being objective and quick to mark) in that they are precise and be carefully prepared. Free responses written by the $S$ are sometimes so expressed that it is difficult to know whether comprehension has occurred. However, this type of response is virtually obligatory at the highest level of question, which requires $S$ to give his opinion, attitude or subjective reaction to aspects of the passage.

If you confine yourself to affirming $\mathrm{Ss}$ ' correct answers, you provide feedback, but are merely testing rather than ensuring that Ss have comprehended. Where it is clear that the passage has been comprehended, this is sufficient. In most cases, however, Ss need more information. They need to know why their answer is wrong and why another is right. To go beyond testing, class discussion can be used to clarify the correct answer, for it is beneficial, especially at intermediate levels, to examine miscomprehension, which may have arisen from mis-hearing or mis-reading. Discussion is particularly useful as the class rarely has a shared experience.

Some writers, e.g. Sheerin, argue that transcripts should be made available during or after the listening activity, particularly for remedial work. In our opinion, this is a grossly misguided strategy, for if Ss know they will be able to read the script, they will not make so much effort to comprehend aurally. They certainly need confirmation of what they have heard, but the limited time can be put to better use continuing aurally, using discussion and question-and-answer, with the $\mathrm{T}$ playing only a minor part. Where a $S$ errs, you can question the veracity of the erroneous statement, leaving the class to discuss and correct it.

Furthermore, it is not of transcendental importance that the learner should end up with a $100 \%$ correct version of what he has heard. Brown \& Yule's «reasonable interpretation» should be sufficient, and even if this is not reached, attempts to clarify all the details in a LC passage are misplaced because they imply a need to reach a full understanding and may engender anxiety in the $S$ who cannot achieve it.

\section{Integrating the Skill}

Working on the same or closely-related topics, but in different modes, such as reading short extracts or summaries or writing on the subject serve to integrate an imminent listening activity with other language skills. This has the disadvantage of reinforcing mispronunciations (because Ss may subvocalise as they read or write) and preceding pronunciation (RSL) exercises will be advisable.

The LC passages you use may focus on a particular structure, extend vocabulary about a specific topic, or merely reinforce past work. Conversation, interviews, newcasts and documentaries are excellent bases for post-listening activities where Ss can express their own feelings and opinions orally or in writing, writes Glisan (14). Debating in groups, class discussions, group problem-solving, interviewing in pairs, changing the passage to fit one's own ideas, writing character sketches and essays all contribute to relating this skill with others. They reinforce syntactic and semantic knowledge and assist the process of internalizing the new information. 


\section{Other Listening Activities}

Relaxed listening: comparison with his peers' patently higher levels of comprehension creates a pressure for results in the less proficient but motivated listener. This can serve to make him attempt to apply mistaken past strategies. One method of overcoming this is to encourage listening at home, which removes both comparison and anxiety.

If $\mathrm{S}$ watches or listens to world news in his $\mathrm{Ll}$ and then to the world news on the $\mathrm{BBC}$ or VOA, some of the items will coincide. If his aim at first is solely to listen for those words he can recognize (the names of countries and world leaders), and not concern himself with other details, and he does this daily over a period of several weeks, he should find that he is capturing other words too. If he keeps a tally of all the words he recognizes (and later notes down the words and phrases), and keeps a daily record, he will find that he gradually recognizes more and more.

A further advantage of this approach is that the task is always limited in time about ten minutes. If the broadcast is recorded and repeated, however, this will make it into a chore and remove any enjoyment. There is not testing, $\mathrm{S}$ cannot be right or wrong and he should learn to associate listening with a non-anxious state.

There are various features of this approach to remedial listening that are worthwhile emphasizing: one is that the activity requires no preparation at semantic and syntactic levels. The listener simply acquires in Ll very specific world knowledge closely related in content to what he is about to hear in L2. Being recently learnt, the details are easily available and provide an easily attainable comprehension target. No concessions are made in terms of rate of speech, the language and its delivery are intended for competent listeners. S would do well to bear this in mind, as he should have some justification at the start for poor performance. This also means that there is no time for attempting simultaneous translating. S should try top be aware of his attempts at this, and note that he may miss more information while translating than he gains from translating. He should come to realize that he must choose between translating and redircting his attention to the speaker.

An argument against using broadcasts has been mooted by Geddes, who suggests that because newscasts are written discourse read aloud and not spontaneous, they do not meet S's needs. In terms of the sort of listening Ss will eventually require, this is true. Here, however, we propose home listening to broadcasts primarily to reduce anxiety, and secondarily to train $S$ in recognizing what he can.

Note-taking: taking notes while listening is also a skill that can be trained. As it requires attention-switching between message and activity, it presupposes a higher level of proficiency. Ideally, note-taking involves noting the key ideas of the previous paragraph or block of ideas while attending to those of the current one, although this appears to be a skill not necessarily available to all. More accessible is noting the key ideas of the previous sentence.

Training in note-taking can be carried in class with passages new to Ss, but using vocabulary and syntax well within their capacity, and using familiar topics, these factors being raised one at a time until $S$ can satisfactorily take notes on material at his proficiency level. S's ability to reconstruct the main thrust of the passage from the notes would constitute the task target. 


\section{The Language Laboratory}

The laboratory has its place, but its use should be carefully directed. Since our principal aim in teaching $\mathrm{LC}$ is to wean $\mathrm{S}$ away from translating while listening, our work will be undone in the laboratory if S aims for $100 \%$ comprehension and advances through a passage phrase by phrase translating each one.

For those Ss who have not responded adequately to classroom training, the laboratory will provide remedial practice. However, if Ss must be adjured to listen to whole paragraphs or several sentences of dialogue, with the conscious aim of avoiding translation, and to lower his comprehension target to that of capturing the broad ideas of the message. Further, if he limits himself to two or three passes and works on a large variety of material, he will benefit his skill far more than if he intensively works a few, or even just one message.

It is difficult, however, to regard laboratory listening as an activity as potentially beneficial as relaxed listening. S's whole attitude in approaching laboratory work, unless is advised to the contrary, is likely to be a grim, tense 'I'm going to understand everything', which means trying to comprehend every word, while what we are trying to train is gist or global comprehension. For any learner this means a «let me see how much I can get from this» approach, and it does not matter if he does not get very much.

\section{Notes}

1. The only English words which can be pronounced phonemically are most CVC, CVCC and CCVC monosyllables containing the letter 'e,' such as met, tent and bred, but not those ending in semi-vowels-new/knew and key. Apart from this group, there are few words, like on, off and not, which can be pronounced like they are written.

2. The importance of the Spanish vowel is clearly demonstrated in the following: $a$ casa, acaso, acoso, o casa, o cosa, o coso, acuso, where the vowels contribute as much to meaning as the consonants. This does not obtain in English, and has enormous implications for LC. Firstly the S attends to each syllable (important in Spanish), and reports that that speech is too rapid. Secondly, he must learn to listen primarily to the stressed syllables as part of larger meaning groups, paying only incidental attention to the reduced forms (a difficult feat when you do not this in your mother tongue).

3. Consider oposiciones; these typically deal exhaustively with facts; even practical knowledge must be expounded theoretically. Actually doing the job often requires very different knowledge from that examined. (Has anyone ever failed prácticas?) Another good example is the driving test, which consists of an exhaustive written examination on the highway code, while the business of driving the car plays only a minor part, standards of acceptable manipulative ability being relatively low. In England, the culture stresses the practical side. The entire driving test consists of driving in local traffic conditions, including a simulated emergency stop, with only one or two oral questions about the more pertinent facts of the code, which have been practically examined in the driving. The test is so demanding that $70 \%$ fail on their first attempt, and nearly half on their second.

4. I was fortunate enough to prepare and teach an English course phonetically to municipal policemen (Eastman). They saw no 'real' written English, learnt vocabulary very quickly, spoke 
it with no Spanish accent, and had no problems recognizing what words and phrases they knew when these were embedded in questions and statements.

5. English pronunciation can be simplified into a schema as follows;

monosyllables

polysyllables

function words

$\begin{array}{lllll}\text { a } & \text { am an are as } \\ \text { at } & \text { but can could do } \\ \text { does for had } & \text { has have } \\ \text { he her him } & \text { his I } \\ \text { if } & \text { is } & \text { it } & \text { its me } \\ \text { must my of } & \text { on shall } \\ \text { should so than that the } \\ \text { their them till to up } \\ \text { us was were will with } \\ \text { would you your }\end{array}$

Except for those containing ' $i$,' most reduce to schwa. Interestingly, the function words make up around $25 \%$ of all written and spoken English.

content words

pronounced accordingly

\author{
most have one stressed syllable, all others being reduced to \\ schwa or short ' $\mathrm{i}$ ' \\ Exceptions: compound words like aeroplane, \\ armchair, understand \\ words ending in '-o' or '-ow' \\ tomato /ta'ma:təu/ \\ potato /pa'teitəu/ \\ window /'windəu/
}

\title{
Works Cited
}

Arnold, D. J. and P. H. Brooks. «The Influence of Contextual Organizing Material on Children's Listening Comprehension.» Journal of Educational Psychology 68 (1976): 711-16.

Brown, G. «Investigating Listening Comprehension in Context.» Applied Linguistics 7.3 (1986): 284-303.

Brown, G. and G. Yule. Teaching the Spoken Language. Cambridge: Cambridge U P, 1983.

Chamot, A. D. and L. Kupper. «Leaming Strategies in Foreign Language Instruction.» Foreign Language Annals 22.1 (1989): 13-24.

Eastman, J. K. «Simplified Phonetic for Spanish Policeman.» System 16.2 (1988): 207-12. 
Geddes, M. «Listening.» Communication in the Classroom. Ed. Johnson and Morrow. London: Longman, 1981. 78-81.

Glisan, E. W. «A Plan for Teaching Listening Comprehension.» Foreign Language Annals 21.1 (1988): 9-16.

Hutchinson, T. Project English. Oxford: Oxford U P, 1984.

Johnson, K. and K. Morrow. Communication in the Classroom. London: Longman, 1981.

Mueller, G. «Visual Context Cues and Listening Comprehension: An Experiment.» Modern Language Journal 64.2 (1980): 39-52.

O'Malley, J. M., A. U. Chamot and C. Walker. «Some Applications of Cognitive Theory to Second Language Acquisition.» Studies in Second Language Acquisition 9 (1987): 287-306.

O'Malley, J. M., A. U. Chamot and L. Küpper. «Listening Strategies in Second Language Acquisition.» Applied Linguistics 10 (1989) 418-37.

Sheerin, S. «Listening Comprehension: Teaching or Testing?» English Language Teaching Journal 41.2 (1987): 126-31.

Schiffrin, R. M. and W. Schneider. «Controlled and Automatic Information Processing: II Perceptual Learning, Automatic Attending and a General Theory.» Psychological Review 84 (1977): 127-90.

Swan, M. \& K. Walker. The Cambridge English Course. Cambridge: Cambridge U P, 1984.

Ur, P. Teaching Listening Comprehension. Cambridge: Cambridge U P, 1984. 